\title{
A ORDENAÇÃO DO TRABALHO INFORMAL: CONFLITOS NO/PELO TERRITÓRIO
}

\author{
Adma Viana SANTOS 1 \\ Erica Aparecida Vaz ROCHA²
}

\begin{abstract}
RESUMO
A dimensão real/concreta do processo de exploração do trabalho, se apresenta como um fenômeno complexo na sociedade capitalista contemporânea, transcendendo a dualidade entre formalidade e informalidade do mercado de trabalho. No caso dos vendedores ambulantes, por exemplo, mesmo que em âmbito nacional haja um incentivo para que se tornem um Microempreendedor Individual (MEI), surgem questionamentos sobre até que ponto esta representa uma condição social de menor degradação. Assim, o objetivo dessa pesquisa foi o de analisar o processo de precarização do trabalho a que se encontram submetidos os trabalhadores informais, na especificidade do comércio ambulante do centro comercial principal da cidade de Vitória da Conquista/BA, base empírica da presente pesquisa, onde foram realizadas entrevistas e aplicados questionários à 340 trabalhadores. Além da relação imbricável entre os processos de precarização do trabalho, do desemprego e da informalidade no atual estágio de acumulação capitalista, esta pesquisa mostrou a atuação do Estado enquanto agente regulador, legitimador e ao mesmo tempo limitador do mercado informal, bem como a realidade vivenciada pelos comerciantes ambulantes, marcada pela precarização de suas condições de vida e de trabalho.
\end{abstract}

Palavras-chave: Precarização. Trabalho informal. Comércio ambulante. Estado. Sistema capitalista.

\section{THE ORDINATION OF INFORMAL WORK: CONFLICTS IN/BY THE TERRITORY}

\begin{abstract}
The real/concrete dimension of the labor exploitation process is presented as a complex phenomenon in contemporary capitalist society, transcending the duality between formality and informality in the labor market. In the case of street vendors, for example, even if there is an incentive at national level to become an Individual Microentrepreneur, questions arise about the extent to which this represents a less degraded social condition. Thus, the objective of this research was to analyze the process of precarious work that informal workers are subjected to, in the specificity of street commerce in the main commercial center of the city of Vitória da Conquista, Bahia, Brazil, the empirical basis of this research, where interviews and questionnaires were applied to 340 workers. In addition to the

\footnotetext{
${ }^{1}$ Doutora em Geografia pela Universidade Estadual Paulista (UNESP) - Campus Rio Claro. Professora Substituta do Instituto Federal Goiano - Campus Urutaí. E-mail: adelu.2010@gmail.com

2 Doutora em Geografia pela Universidade Federal de Uberlândia (UFU). Professora Adjunta do Instituto Federal Goiano - Campus Urutaí. E-mail: erica.vaz@ifgoiano.edu.br
} 
imbricable relationship between the processes of precarious work, unemployment and informality in the current stage of capitalist accumulation, this research showed the role of the State as a regulating, legitimizing agent and at the same time limiting the informal market, as well as the experienced reality by street traders, marked by the precariousness of their living and working conditions.

Keywords: Precariousness. Informal work. Street commerce. State. Capitalist system.

\section{LA ORDENACIÓN DEL TRABAJO INFORMAL: CONFLICTOS EN/POR EL TERRITORIO}

\section{RESUMEN}

La dimensión real / concreta del proceso de explotación laboral se presenta como un fenómeno complejo en la sociedad capitalista contemporánea, trascendiendo la dualidad entre formalidad e informalidad en el mercado laboral. En el caso de los vendedores ambulantes, por ejemplo, incluso si a nivel nacional existe un incentivo para convertirse en un microempresario individual, surgen preguntas sobre hasta qué punto esto representa una condición social menos degradada. Por lo tanto, el objetivo de esta investigación fue analizar el proceso de trabajo precario al que están sometidos los trabajadores informales, en la especificidad del comercio callejero en el principal centro comercial de la ciudad de Vitória da Conquista, Bahia, Brasil, la base empírica de esta investigación, donde Se aplicaron entrevistas y cuestionarios a 340 trabajadores. Además de la relación imbricable entre los procesos de trabajo precario, el desempleo y la informalidad en la etapa actual de acumulación capitalista, esta investigación mostró el papel del Estado como agente regulador, legitimador y, al mismo tiempo, limita el mercado informal, así como la realidad experimentada por comerciantes callejeros, marcados por la precariedad de sus condiciones de vida y trabajo.

Palabras clave: Precariedad. Trabajo informal. Comercio callejero. Estado. Sistema capitalista.

\section{INTRODUÇÃ̃}

Sabe-se que o sistema de produção capitalista se fundamenta em uma busca incessante pelo lucro, fato que se concretiza mediante o imenso esforço, por parte dos capitalistas, em reproduzir de modo ampliado o capital. Trata-se de um sistema que passa por períodos de expansão e também de recessões.

Entretanto, neste século XXI, o capitalismo tem se revelado sob uma profunda crise com dimensões jamais constatadas até então, sendo, por tanto, considerada por Mészáros (2002) como uma verdadeira crise estrutural, na qual as contradições inerentes a este sistema atingem limites verdadeiramente 
históricos. Esse conflitante cenário acaba por repercutir em profundas mudanças no mundo do trabalho, na medida em que gera impactos diretos na forma de utilização e exploração da mão de obra por parte dos capitalistas em função, sobretudo, da exploração intensa e da alienação dos trabalhadores, o que intensifica as condições de vulnerabilidade.

É importante ressaltar que essas profundas mudanças no mundo do trabalho tornaram-se possíveis mediante o processo de reestruturação produtiva do capital que, por sua vez, possibilitou um desenvolvimento tecnológico e organizacional do modo de produção capitalista, o que, entre outras coisas, conduziu a uma diminuição relativa do capital variável (força de trabalho) em relação ao capital constante (meios de produção). Apesar de tratar-se de uma tendência histórica, na atualidade da reestruturação produtiva verifica-se que o crescimento da composição orgânica do capital ganha dimensões radicais elevando, assim, o fenômeno do desemprego, o processo de exploração do trabalho e da extração da mais-valia à níveis cada vez mais estruturais.

Nesse contexto, se observa que a precarização tem atingido inclusive setores formais da economia, com redução de salários e de benefícios, intensificação da jornada de trabalho, estabelecimento de contratos temporários de trabalho, entre outros.

Aos trabalhadores desempregados, por sua vez, resta recorrer às atividades informais, por exemplo, como forma de geração de ocupação e renda. Assim, pode-se então dizer que o trabalho informal tem se apresentado como uma das alternativas encontradas por um número cada vez maior de trabalhadores excluídos do mercado de trabalho formal.

Deste modo, pode-se verificar a existência de uma relação altamente imbricável entre os processos de desemprego, expansão do setor informal e precarização das condições de trabalho no atual estágio de acumulação capitalista. Assim sendo, para uma maior compreensão destes fenômenos, acredita-se ser necessário o estudo das formas de controle da subordinação e subsunção do desemprego e do trabalho informal ao capital. Na presente pesquisa, tal análise foi proposta evidenciando-se a atuação do Estado sobre o 
mundo do trabalho, por meio de seus mais variados instrumentos de regulação/ controle.

Os Estados nacionais são considerados como sendo a maior instituição jurídica e de poder político que se exerce sobre um povo ou nação (PIRES, 2015). Esta instituição incube-se de garantir a relação de coesão e coexistência dos órgãos e das leis que dominam sobre um território (GRUPPI, 1985, apud PIRES, 2015), de modo que sua atuação foi, e ainda tem sido, crucial nas modernas sociedades capitalistas, mesmo que seu papel na economia e na sociedade tenha sido redefinido ao longo dos tempos.

Considera-se, ainda, que essa instituição se configura em um agente social cuja atuação na organização territorial se dá de forma complexa, uma vez que reflete os mais diversos interesses dos diferentes membros que compõem a sociedade de classes. Verifica-se também que são amplas as possibilidades de sua atuação, na medida em que o Estado pode:

[...] atuar diretamente como grande industrial, consumidor de espaço e de localizações específicas, proprietário fundiário e promotor imobiliário, sem deixar de ser também um agente de regulação do uso do solo e o alvo dos chamados movimentos sociais urbanos (CORRÊA, 1995, p. 24).

Cabe também frisar que a atuação do Estado se faz dentro de um marco jurídico, processando-se basicamente em três níveis político-administrativos e espaciais: federal, estadual e municipal. Souza (2006) considera que é na escala local que a participação política direta se mostra mais viável. Segundo esse autor, é a esta escala que se encontram vinculados os níveis mais inferiores da administração, de modo a representar uma situação de maior proximidade com a sede do poder estatal (Estado local).

Assim, verifica-se que a atuação do poder público municipal, no processo de construção do espaço urbano, se pauta em decisões que influenciam e também sofrem interferência de outros agentes envolvidos na vida da cidade, e isso considerando-se os imperativos de ordem econômica, política e social. Sobre isso, Daniel (1998 apud FERRAZ, 2001, p. 146), faz a seguinte observação:

[...] as decisões políticas emanadas da Prefeitura constituem o resultado de entrechoques de um sem-número de 
micropolíticas [...]. O governo, implícita ou explicitamente, possui determinado projeto político, que é implementado com alterações ou substituído por outra orientação, em função desse conjunto de entrechoques e da influência dos diversos poderes.

Adicionalmente, esse autor enfatiza que as ações do poder público de uma localidade, encontram-se sujeitas também à influência de condicionamentos conjunturais que transcendem o espaço municipal, estando, desse modo, associada a um conjunto de fatores tanto internos quanto externos ao campo político local.

Horwood e Boyce (1959 apud CORRÊA, 1995), chamam a atenção para o centro das cidades enquanto principal núcleo de articulação do espaço urbano municipal, cuja organização se dá em função dos diferentes usos do solo, considerando-se que é na área central das cidades capitalistas que se concentram atividades comerciais, prestação de serviços diversos e os terminais de transportes intraurbanos. Pode-se ainda dizer que esta configura-se em uma área de decisões, visto que nela:

[...] localizam-se as sedes sociais ou escritórios regionais das principais empresas que atuam na cidade e em sua região de influência. O Estado tem aí muitas de suas instituições. É assim o ponto focal da gestão do território (HORWOOD; BOYCE, 1959 apud CORRÊA, 1995, p. 42).

Lima (2008) demonstra concordar com tais autores, ao afirmar que o centro comercial de uma cidade capitalista é o lugar da concentração das mais diversas atividades de comercialização de bens e serviços diversificados, desde lojas de eletroeletrônicos, de eletrodomésticos, de departamentos, em escalas diferentes, à prestações de serviços e trabalhadores informais. É também nesta localidade que se encontram uma diversidade de empresas e instituições que constituem a sua dinâmica atual, alavancando o comércio e a prestação de serviços. Segundo essa autora, a área central trata-se do lugar de maior expressão do capitalismo em uma cidade, na medida em que se constitui em um espaço de consumo para as mais diversas classes sociais.

Assim sendo, apesar do processo de descentralização da área central, que vem ocorrendo em função da existência de novas áreas com expansão urbana comercial, verifica-se que o centro comercial principal ainda expressa uma forte 
centralidade, sobretudo em cidades pequenas e médias brasileiras, como é o caso de Vitória da Conquista/BA.

A referida cidade abrange uma área de $3.705,838 \mathrm{~km}^{2}$, com uma população estimada de 338.885 pessoas em 2018 , sendo a terceira maior cidade do estado, atrás de Salvador e Feira de Santana. Possui um PIB per capita de R\$ 16.785,34, ocupando a $37^{\circ}$ posição no estado da Bahia e a $2400^{\circ}$ no Brasil. Apresenta ainda um índice de Desenvolvimento Humano (IDH) de 0.678 (IBGE, 2018).

Mapa 1 - Localização da cidade de Vitória da Conquista/BA

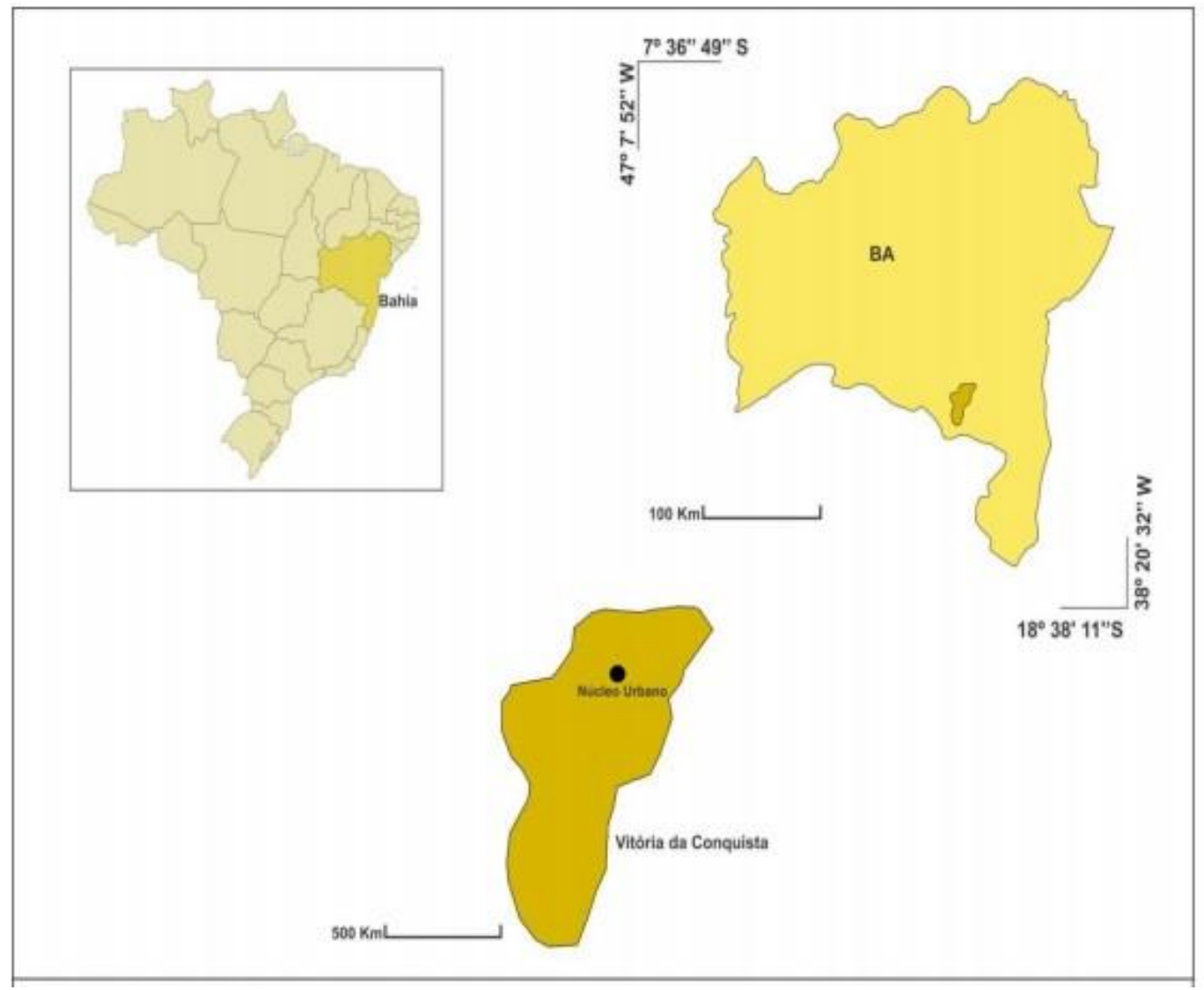

Base cartográfica: IBGE, 2012.

Elaboração: Patrícia H. Milani, 2015.

Importante ainda destacar que esse município se estabelece como principal centro regional, polarizando cerca de 80 municípios na Bahia e no norte do estado de Minas Gerais. Acredita-se que isso decorre, principalmente, do grau de especialização de serviços e atividades produtivas concentradas em seu tecido urbano, tendo no setor de comércio e de serviços suas principais 
atividades econômicas, estando entre os 100 maiores centros urbanos do país. Sua economia tem ainda uma significativa contribuição do segmento industrial, principalmente com a indústria de transformação. Vitória da Conquista influencia, assim, uma população aproximada de 2 milhões de pessoas, representando 17\% da população baiana (ABREU, 2011; PMVC, 2015; VIANA, 2009).

No centro comercial principal desta cidade, ainda se observa um uso comercial e de prestação de serviços muito diversificados e uma organização socioespacial bastante complexa, bem como uma grande circulação e fluxos de pessoas, mercadorias e capitais, que possibilitam o consumo e a dinâmica econômica desse espaço. Deste modo, pode-se dizer que o centro comercial funcional conquistense ainda se mantém como local de concentração das principais atividades econômicas, podendo-se observar a presença de atividades comerciais formais e informais coexistindo nesse espaço, constituindo-se, assim, em zonas de conflito na luta pelo território (LIMA, 2008).

Torna-se, então, necessário um melhor entendimento do processo de regulação do mundo do trabalho por parte do Estado, bem como a expressão territorial dessa relação na organização espacial do centro comercial de Vitória da Conquista (dimensão empírica da presente pesquisa).

Assim sendo, esta pesquisa teve como objetivo analisar o processo de precarização do trabalho a que se encontram submetidos os trabalhadores informais, no contexto do desemprego estrutural e da reestruturação produtiva do capital, bem como verificar a questão da lógica da organização/estruturação territorial do comércio ambulante no centro comercial de Vitória da Conquista/BA.

Para o desenvolvimento da pesquisa foi de total importância estabelecer e analisar a categoria que sustenta o entendimento do objeto de estudo proposto. No caso específico da pesquisa, as categorias de análise foram território e trabalho, ressaltando a relação contraditória existente entre eles. Sabe-se que são diversas as formas de abordagem metodológica e conceitual para a compreensão do território sendo, portanto, campo de amplos debates. Contudo, na presente pesquisa a análise dessa categoria geográfica restringe-se as relações de poder entre capital e trabalho (que se estabelecem no território), mediadas pelo Estado. 
Para o desenvolvimento da fundamentação teórica, foram realizadas leituras como subsídio a esta discussão por meio de autores como Pires (2015); Durães (2007); Lima (2008); Alves e Almeida (2009), entre outros. O amadurecimento destas leituras permitiu uma melhor observação e desenvolvimento da dimensão empírica da pesquisa, sobretudo nos direcionamentos e busca de informações e dados.

Para o atendimento dos objetivos propostos e seguindo a orientação teórica, a pesquisa empírica foi estabelecida com a realização de entrevistas e aplicação de questionários à 146 trabalhadores informais dos dois principais pontos de concentração de trabalhadores informais no centro comercial de Vitória da Conquista/BA (sendo eles a Praça Arlindo Rodrigues - Feira do Paraguai - e a Praça da Bandeira), correspondendo a uma amostra de 40\% de uma população de 364 trabalhadores informais desta localidade, representando um conjunto tendencial importante e significativo para a análise. Procurou-se, assim, buscar compreender as reais relações/condições de trabalho a que estão submetidos esses trabalhadores desempregados no atual estágio de acumulação capitalista.

Para um melhor entendimento do processo de controle/regulação do mundo do trabalho, por parte do Estado, bem como a expressão territorial dessa relação na organização espacial do centro comercial de Vitória da Conquista, fez-se também necessário realizar um levantamento documental por meio de pesquisas em órgãos públicos (Prefeitura Municipal, Câmera de Vereadores, secretarias municipais, Ministério do trabalho, etc.). Isto foi feito com o objetivo de identificar como se dá a atuação desses órgãos com relação à regularização, legitimação e limitação desse tipo de comércio fundamentado na informalidade.

Esta pesquisa esteve amparada pelo constante movimento indissociável de observações em campo, análise dos dados obtidos, leituras e discussões. A análise se estabeleceu pelo posicionamento crítico no levantamento das contradições do processo histórico de desenvolvimento do setor informal e de precarização das condições de trabalho no centro comercial de Vitória da conquista. 


\section{A ordenação do trabalho informal}

De um modo geral, pode-se dizer que a atuação do Estado no espaço urbano capitalista, visa criar condições que viabilizem o processo de acumulação e a reprodução das classes sociais, de modo a tornar viáveis tanto a atividade econômica, como também o processo de diferenciação social (CORRÊA, 1995). No caso da cidade de Vitória da Conquista, percebe-se o interesse público no fortalecimento das atividades comerciais e de serviços na área central desta cidade, podendo-se verificar no próprio Plano Diretor Urbano do município (PDU), a presença de diretrizes que visam, principalmente, o fortalecimento do centro tradicional de comércio e serviços (promovendo a sua requalificação e melhoria), bem como a implantação de novos empreendimentos privados nessa localidade.

O PDU de Vitória da Conquista foi fruto de um convênio firmado entre a Prefeitura Municipal e a Universidade Federal da Bahia (UFBA), sendo elaborado com a finalidade de ordenar o crescimento da cidade, bem como acompanhar, de modo mais direto, o ordenamento e o parcelamento do solo (FERRAZ, 2001).

Vale ressaltar que:

Na segunda metade da década de 1970 as preocupações com o planejamento urbano, bem como exigências federais para fins de liberação de financiamentos, incentivaram o poder público municipal a elaborar o Plano Diretor Urbano, sancionado através da Lei $\mathrm{n}^{\circ} 118 / 76$, em 22 de dezembro de 1976, pelo então prefeito Jadiel Vieira Matos (FERRAZ; ALMEIDA, 2007, p.4).

Cabe também frisar que, em 2006, o PDU de Vitória da Conquista foi aprovado e instituído como um instrumento normativo da política de desenvolvimento urbano, através da Lei $n^{0}$ 1.385/2006. Dentre os seus vários princípios norteadores, pode-se destacar o que diz respeito à necessidade de fortalecimento do papel regulador do setor público e valorização das suas funções de planejamento, controle e articulação. Com relação ao planejamento da organização territorial, o entendimento é o de que devem ser priorizadas as atividades econômicas, comerciais e de serviços consideradas estratégicas para 
o desenvolvimento do município, atentando-se para uma adequada distribuição das mesmas no território.

Entretanto, além do Plano Diretor Urbano de Vitória da Conquista, há o uso de outros instrumentos de política administrativa no que concerne a organização territorial do espaço urbano do município. Como exemplos podem ser citados o Código de Polícia Administrativa (Código de Posturas) e o Código Tributário.

Com relação ao Código de Polícia Administrativa (Código de Posturas), verifica-se que o mesmo tem como finalidade estabelecer normas de polícia administrativa de competência do município em matéria de proteção ao meio ambiente, a saúde e a ordem pública; a ele compete também regular as relações entre o poder público local e os munícipes, bem como o funcionamento dos estabelecimentos comerciais, industriais e prestadores de serviços, de acordo com Dec-Lei n ${ }^{\circ}$ 695/93 de 02 de fevereiro de 1993.

No que diz respeito à regulação das atividades comerciais, verifica-se no referido Código a proibição do funcionamento de qualquer tipo de estabelecimento comercial, inclusive os de caráter eventual, no território do município sem a licença prévia (pessoal e intransferível) da administração municipal. É válido ressaltar que a concessão da licença deverá sempre obedecer às normas de vigilância sanitária, do Código de Obras, do Código Ambiental, do Código de Polícia Administrativa e do Código Tributário do município de Vitória da Conquista.

Para o exercício do comércio eventual, o interessado necessita também se matricular no cadastro geral de contribuintes do município, sendo que a prioridade é concedida, pelo poder executivo municipal, às pessoas sindicalizadas ou deficientes físicos, isto de acordo com o artigo 136 do Código de Posturas do município de Vitória da Conquista.

Importa frisar que as atividades comerciais de caráter eventual, englobam não somente aquelas exercidas em determinadas épocas do ano (em períodos festivos e comemorações populares), mas também o comércio em instalações removíveis tais como: barracas, tabuleiros, balcões, mesas, trailers e semelhantes, dispostas em logradouros públicos.

Quanto aos locais para o exercício desse tipo de comércio, cabe sinalizar que os mesmos devem ser previamente delimitados pelo poder público 
municipal, de modo a não impedir ou prejudicar o livre trânsito de pedestres ou veículos nas ruas, praças, passeios, estradas e caminhos públicos. Devem ainda apresentar perfeitas condições de higiene e limpeza, cabendo ao comerciante ou prestador do serviço se empenhar para que tais condições sejam mantidas.

Verifica-se que essas exigências se dão de forma mais criteriosa, sobretudo no comércio eventual voltado para o gênero alimentício, observando-se que, além da licença, os ambulantes devem também portar obrigatoriamente a caderneta do Serviço de Fiscalização de Polícia Administrativa (SFPA) e um atestado médico que demonstre não existir impedimentos para o exercício deste tipo de comércio, isto de acordo com o artigo 135 do Código de Posturas do município.

Já com relação aos horários de funcionamento, observa-se que os estabelecimentos comerciais, de um modo geral, têm liberdade de funcionamento nos dias úteis, sábados e domingos, desde que sejam observadas as determinações da legislação do trabalho aos empregados. A não observância das referidas exigências, poderá implicar na apreensão de mercadorias postas à venda, bem como na aplicação de multas, cabendo ao poder executivo municipal e, em geral, aos servidores municipais, zelar pela execução dos instrumentos de Polícia Administrativa por meio da realização de inspeções periódicas, sendo que:

Quando o processo fiscal se referir à aplicação de penalidade, a competência para decidir em primeira instância é a seguinte: I - secretário municipal de serviços públicos, nos casos de cassação de licença e fechamento de estabelecimento comercial; II - coordenador de limpeza e serviços básicos, nos casos de perda de bens e mercadorias e suspensão de licença; e III - chefe da divisão de posturas, nos casos de cassação de matrícula e apreensão de mercadorias e bens (VITÓRIA DA CONQUISTA (município) art. 313, Lei nº 695/1993).

Para o atendimento não somente dessas, como das demais diretrizes do PDU e do Código de Posturas, o município poderá dispor de todos os instrumentos tributários previstos no Estatuto da Cidade. Sob tal justificativa, impõe-se então a cobrança de taxas também para exploração de atividades em logradouros públicos, devendo essas corresponder às despesas do município concernentes a fiscalização e vistoria dos diversos estabelecimentos (VITÓRIA DA CONQUISTA (município), Lei n ${ }^{\circ}$ 1.385/2006).

No caso específico do exercício de comércio eventual ou ambulante, o 
pagamento da taxa deve ser realizado no início da atividade (antes mesmo da concessão do alvará de licença), bem como nos casos de renovação da licença (anualmente), de acordo com o Dec-Lei n ${ }^{\circ}$ 1.259/2004 de 22 de dezembro de 2004, que institui o Código Tributário do município de Vitória da Conquista.

Tanto a ausência de requerimento da licença para o início de exploração da atividade, a falta de recolhimento da licença anual, bem como falsa declaração para obtenção da isenção da taxa, são consideradas infrações ao Plano Diretor Urbano do município e ao Código de Polícia Administrativa, ficando o infrator sujeito ao pagamento de multas (cujo valor é correspondente ao tipo de infração).

Além da aplicação de multas, pode ainda ocorrer apreensão de mercadorias e documentos que constituam prova material de infração à legislação tributária do município. A depender do caso, após a apreensão, esses bens poderão ser leiloados ou até mesmo doados a instituições de caridade e demais entidades de assistência social.

Verifica-se ainda que a concessão de qualquer isenção de tributos referidos no Código Tributário municipal, somente poderá se efetivar através de lei municipal específica, de modo que ficam isentos da taxa os deficientes físicos, visuais, excepcionais e inválidos que exerçam (individualmente) pequeno comércio ou prestação de serviços. Cabe à Secretaria de Finanças, pelos órgãos especializados, assegurar o cumprimento das normas da legislação.

Em âmbito nacional, nos últimos anos tem sido observado um incentivo para que trabalhadores informais (dentre os quais se incluem os vendedores ambulantes), saiam da informalidade e se tornem um Microempreendedor Individual (MEI) instituído pela Lei Complementar $n^{0}$ 128/2008 que alterou a Lei Geral da Micro e Pequena Empresa - ao recolherem contribuições para a Previdência Social e impostos para estados e municípios (PORTAL DO EMPREENDEDOR, 2020). De acordo com o SEBRAE (2020), pode ser enquadrado como Microempreendedor Individual o profissional autônomo que receba a renda máxima bruta de até $\mathrm{R} \$ 81$ mil reais por ano ou $R \$ 6.750$ reais por mês.

Embora este mecanismo tenha entrado em vigor em julho de 2009, inicialmente ele se aplicava apenas no Distrito Federal e em alguns estados brasileiros: Rio de Janeiro, São Paulo, Minas Gerais, Rio Grande do Sul, Santa 
Catarina, Paraná, Ceará e Espírito Santo (TAVARES, 2010). A extensão do registro do MEI para todo o país ocorreu em o9 de fevereiro de 2010.

Os interessados terão como despesas o pagamento mensal do Simples Nacional, contribuindo com os seguintes valores: R \$ 53,25; R 57,25 e R \$ 58,25 referentes ao comércio ou indústria, prestação de serviços e comércio e serviços juntos, respectivamente. Destaca-se ainda que:

O cálculo corresponde a $5 \%$ do limite mensal do salário mínimo e mais R\$ 1,oo (um real), a título de ICMS, caso seja contribuinte desse imposto e/ou $\mathrm{R} \$ 5$,oo (cinco reais), a título de ISS, caso seja contribuinte desse imposto (SEBRAE, 2020).

Ao recolher esses valores, o Microempreendedor Individual, adquire direitos trabalhistas e previdenciários que anteriormente não tinha na condição de trabalhador informal, tais como: possibilidade de legalização do negócio; direito aos benefícios da Previdência Social; registro da empresa no Cadastro Nacional das Pessoas Jurídicas (CNPJ); comprovação de renda (o que poderia facilitar a aquisição de empréstimos bancários com taxas reduzidas); possibilidade de emissão de notas fiscais mediante vendas de mercadorias, dentre outras (PORTAL DO EMPREENDEDOR, 2020; SEBRAE, 2020).

No entanto, é preciso se atentar também para as limitações dessas medidas, de modo a se verificar até que ponto de fato se constituem em vantagens reais para os trabalhadores informais, de forma a oferecer melhorias significativas nas condições de trabalho e de vida.

No caso dos comerciantes ambulantes de Vitória da Conquista, compreende-se que essa atividade, apesar de ser uma importante fonte de ocupação e renda, traz consigo inúmeras desvantagens para esses trabalhadores. Dentre os entrevistados, $86,6 \%$ consideram o trabalho nas ruas como sendo um dos principais problemas enfrentados diariamente: infraestrutura inadequada do local de trabalho; sujeição à situações de violência (roubos e assaltos), bem como às intempéries climáticas, etc. 8,6\% declararam ter problemas com a Prefeitura Municipal e com demais órgãos governamentais responsáveis pela fiscalização; 2,9\% alegaram sofrer forte discriminação social, de modo a se sentirem à margem da sociedade; $1,9 \%$ declararam existir ainda atritos entre colegas, de modo a prejudicar o bem estar do ambiente de trabalho. 
Verificou-se, ainda, que a maioria dos entrevistados (56\%), possui uma renda média mensal equivalente ou mesmo inferior a um salário mínimo, sendo essa considerada insuficiente para o sustento dos mesmos, bem como de suas famílias. Dentre esses, 25,7\% declararam realizar ainda outros tipos de atividades (caracterizadas também pela precarização) de modo a complementar a renda familiar diante da constante insegurança financeira.

Com relação a jornada de trabalho, a maioria $(89,5 \%)$ afirmou trabalhar em média 10 a 12 horas por dia; 7,6\% dos entrevistados afirmaram trabalhar por um período superior a 12 horas diárias e 2,9\% afirmaram cumprir uma jornada diária de 8 a 10 horas. Considera-se que essa intensa jornada diária de trabalho implica em uma série de desgastes físicos e psicológicos, acabando por repercutir na questão da própria qualidade de vida desses trabalhadores.

É preciso ainda reconhecer a existência de um conjunto de fatores que contribuiu não somente para a inserção, como também para a permanência nesse tipo de atividade. $61 \%$ dos trabalhadores entrevistados declararam ser a falta de opção, mediante uma situação de desemprego, a principal 'motivação' que inicialmente os conduziram ao comércio informal; 39\% afirmaram conhecer pessoas que já trabalhavam nesse tipo de atividade, as quais serviram como referência.

Todos esses aspectos mencionados remete a questão da intensa precarização das condições/relações de trabalho, uma vez que são inúmeros os problemas enfrentados por esses trabalhadores diariamente. Entretanto, a maioria dos trabalhadores entrevistados manifestou uma verdadeira ausência de perspectiva para a troca de atividade laboral, e os motivos citados foram diversos: a constatação da intensa precariedade no mundo do trabalho que atinge também o setor formal (uma vez que a simples inserção não configura garantia de segurança e estabilidade); a idade avançada; o baixo nível de escolaridade de muitos desses trabalhadores, sendo estes os principais motivos elencados.

A seguir, veremos a expressão espacial dessa relação de regulação/ controle sobre o trabalho informal, bem como sua influência na organização territorial do espaço urbano capitalista. 


\section{A "desordem": conflitos no/pelo território}

Mediante as diversas formas de regulação do mundo do trabalho através do aparato burocrático-institucional do Estado moderno, faz-se também necessária a busca por uma maior compreensão do modo como essa relação se expressa territorialmente na especificidade do espaço urbano de Vitória da Conquista, mais precisamente no centro comercial desta cidade.

Mas, importa antes ressaltar que, além do Estado, há outros atores sociais que atuam como personificação/representação de diferentes classes com diversos interesses no processo de construção do espaço urbano. Castro (2005, p. 41), chama a atenção para a questão da territorialização das questões e dos conflitos de interesses dos mais diversos atores sociais, na medida em que esses:

[...] materializam-se em disputas entre esses grupos e classes sociais para organizar o território da maneira mais adequada aos objetivos de cada um, ou seja, do modo mais adequado aos seus interesses. Essas disputas no interior da sociedade criam tensões e formas de organização do espaço que definem um campo importante da análise geográfica.

Assim, verifica-se a existência de arranjos territoriais como expressão das disputas e tensões produzidas por diferentes conflitos de interesses na sociedade capitalista. É preciso que se compreenda que é no território que essas relações sociais se concretizam, na medida em que este se constitui em base material e simbólica da sociedade, bem como arena dos interesses e das disputas de diferentes tipos de atores sociais (CASTRO, 2005).

Contudo, é importante ressaltar a diferença na abrangência do impacto das ações desencadeadas pelos mais diversos atores sociais. Especificamente com relação às instituições políticas, considera-se que essas compreendem todo órgão destinado a incorporar (tanto física quanto juridicamente), as regras institucionalizadas que regem o jogo político, sendo as ações das mesmas um modo de controle dos conflitos sociais. Acredita-se ainda que em toda disputa política haja interesses que se encontram vinculados ao território (FERRAZ, 2006). Ao que se refere à atuação dessas instituições, observa-se que:

[...] suas decisões e ações, apoiadas por normas, leis e regulamentos, afetam amplamente diferentes instancias da vida social [...]; onde as ações possuem efeitos necessariamente 
abrangentes em relação à sociedade e ao seu espaço e onde existe a possibilidade do recurso à coerção, pela lei ou pela força legítima (CASTRO, 2005, p. 93).

Desse modo, pode-se dizer que as instituições políticas são social e territorialmente abrangentes em relação à sociedade e ao seu espaço, na medida em que afetam toda a sociedade e todo o território sob a jurisdição da sua ação. Entretanto, o mesmo não pode ser dito das ações de outros atores sociais, na medida em que essas afetam áreas e grupos diretamente vinculados, sendo, portanto, mais restritas (CASTRO, 2005).

Especificamente com relação aos vendedores ambulantes do centro comercial funcional da cidade de Vitória da Conquista, verifica-se a mobilização de alguns desses atores sociais (por meio da organização de sindicatos, associações, etc.), no sentido de promover a organização dos trabalhadores no território, bem como conquistar melhores condições de trabalho. Como exemplos podem ser citados o Sindicato dos Sacoleiros Ambulantes e Camelôs de Vitória da Conquista (SINDSAC), e a Associação de Artesanato Conquistense (AAC).

Criado em 12 de dezembro de 2008, logo após uma operação de fiscalização realizada pela Receita Federal em Vitória da Conquista, o SINDSAC tem como presidente o Sr. Valdemir Pereira, havendo ainda a existência de uma diretoria composta por 18 pessoas que o auxiliam. Segundo o atual presidente, os interessados em se filiar ao sindicato precisam possuir inscrição de ambulante, bem como alvará de funcionamento de seu estabelecimento.

O Sr. Valdemir tem o seu ponto fixo na conhecida "Feira do Paraguai", situada na Praça Arlindo Rodrigues em Vitória da Conquista, local onde trabalha há mais de 20 anos. Segundo ele, cerca de 50\% dos trabalhadores ali presentes já se cadastraram como Microempreendedor Individual. Os demais, principalmente por motivo de desconhecimento, acreditam não ter capital suficiente para abrir uma microempresa sendo que, dentre esses, $12,5 \%$ entendem estar atuando na ilegalidade.

Atualmente há naquele local (Feira do Paraguai), a presença de 179 blocos, em quais são comercializadas uma grande variedade de mercadorias 
(eletroeletrônicos, acessórios para celular, etc.), adquiridas em outros estados brasileiros, bem como no Paraguai.

Do total de pessoas entrevistadas, $9 \%$ declararam adquirir suas mercadorias em Vitória da Conquista, como também em outras cidades da região; $75 \%$ afirmaram comprar suas mercadorias em cidades de outros estados brasileiros, sobretudo em São Paulo, Brasília, Recife e Goiânia; os demais (16\%) alegaram obter suas mercadorias tanto em outros estados nacionais, bem como no exterior.

Assim, esses trabalhadores permitem que uma grande quantidade de mercadorias seja comercializada sem nenhum custo adicional (gastos) por parte das empresas fabricantes com a força de trabalho empregada. Dessa forma, colaboram também para que seja reduzida a distância (espacial e temporal) entre produção e consumo, por meio de uma ampla rede de circulação de mercadorias que se insere em uma divisão territorial do trabalho (SOARES, 2008).

Constatou-se ainda que 62,5\% dos vendedores ambulantes que trabalham na Feira do Paraguai, não se encontram cadastrados no Sindicato dos Sacoleiros Ambulantes e Camelôs de Vitória da Conquista (SINDSAC). Dentre os não filiados, 10\% declararam que não participam por não confiarem; 40\% por não acreditarem que o SINDSAC seja atuante ou tenha algum tipo de força política; os demais trabalhadores (50\%), afirmaram não conhecerem ou saberem pouco sobre o papel desempenhado por esse sindicato.

Entretanto, verificou-se que até mesmo entre os trabalhadores que se encontram filiados ao referido sindicato, 30\% declararam não ter muito conhecimento sobre o seu papel e os 70\% restantes não acreditam na eficácia da sua atuação.

Pode-se perceber, assim, a relação entre o processo de reestruturação produtiva e a fragmentação política dos trabalhadores na esfera do desemprego.

Vale ressaltar que há toda uma luta por parte desses vendedores ambulantes no que concerne à organização/estruturação daquele espaço, de modo a lhes propiciar melhores condições de trabalho.

Ainda com relação ao trabalho realizado por esses vendedores ambulantes, Alves e Almeida (2009, p. 246), entendem que: 
[...] a ocupação de vendedor de produtos industrializados (inclusive piratas: brinquedos, eletro-eletrônicos, etc.) em sua maioria contrabandeados do Paraguai, em barraquinhas (camelôs) trata-se de uma força de trabalho por conta própria ou de empregados sem vínculo. É uma atividade precária, incerta, suscetível ao risco da fiscalização que em determinadas ocasiões resolve controlar o fluxo de mercadorias, principalmente quando busca proteger os interesses de indústrias nacionais ou do capital monopólico internacional, dono de patentes e marcas. São formas de organização do trabalho desenvolvidas pelos sujeitos no intuito de superar as dificuldades de sobrevivência, ao mesmo tempo em que contribuem para a reprodução do capital [...]. Assim, a realização da mais-valia sob as formas adversas concretizadas na "Feira do Paraguai" combina com a forma na qual é produzida, consumando a sanha acumulativa do sistema.

Desse modo, entende-se que a precarização das condições de trabalho acaba por possibilitar a continuidade do ciclo acumulativo das relações capitalistas e isto em escala cada vez mais ampliada.

Além da Feira do Paraguai, pode-se observar ainda a presença de vendedores ambulantes em outros pontos estratégicos do centro comercial de Vitória da Conquista, sobretudo em função do grande fluxo de pessoas que se constituem em potenciais consumidores. Dentre esses pontos estratégicos, a Praça da Bandeira pode também ser citada por tratar-se de um local onde se encontram um número considerável de camelôs que diariamente se instalam nos 142 blocos (barraquinhas) ali presentes. Nesta praça ocorre a comercialização de grande variedade de mercadorias, tais como: bolsas, bonés, bijuterias, artesanatos, confecções, etc.

De acordo com os vendedores ambulantes entrevistados, 6,6\% das mercadorias comercializadas são de fabricação própria; $18,4 \%$ são provenientes de outras cidades da Bahia; mas a grande maioria (75\%), é adquirida em cidades de outros estados, sobretudo em São Paulo, Recife, Belo Horizonte, Goiânia e Florianópolis, o que mais uma vez evidencia a existência de uma rede de circulação de mercadorias possibilitada pelo comércio informal, mediante a redução do espaço-tempo entre a produção e o consumo.

Nesta mesma praça também se encontra o Mercado Municipal de Artesanato de Vitória da Conquista, criado pela Secretaria Municipal de Educação e Cultura, sendo em 24 de outubro de 1991 decretado como sendo de utilidade pública 
municipal e, em 1992, de utilidade pública estadual. Inicialmente, haviam principalmente dois pré-requisitos para as pessoas interessadas em ocupar aquele espaço (interior do mercado): era necessário que estivessem cadastradas na Secretaria de Educação do município e participassem, assiduamente, dos eventos organizados pela Prefeitura Municipal em praças públicas da cidade, bem como das Feiras Livres do Interior realizadas em Salvador (cabendo a Prefeitura Municipal de Vitória da Conquista ajudar nos custos com deslocamento e hospedagem).

O Sr. Osvaldo Fernandes Souza, atual presidente da Associação de Artesanato Conquistense (AAC), relatou que: "no Mercado Municipal de Artesanato conquistense, inicialmente não havia prateleiras, nem portas e nem piso; os trabalhadores que tiveram que organizar o seu espaço de trabalho". Ele ainda comentou que a AAC foi criada com o objetivo de reunir os artesãos da cidade, divulgar de forma organizada o trabalho artesanal e preservar as tradições com a confecção de objetos com diversos materiais feitos manualmente.

Essa Associação conta hoje com a participação de associados que trabalham diariamente nos 43 blocos existentes no interior do Mercado Municipal de Artesanato de Vitória da Conquista, pagando a Prefeitura Municipal uma taxa simbólica no valor de $\mathrm{R} \$ 12$,oo pela ocupação do local. Porém, em virtude da própria limitação de tamanho do espaço, o governo municipal permitiu que vendedores ambulantes ocupassem, também, a calçada em frente a esse Mercado, onde são diariamente dispostas cerca de 30 barracas removíveis.

Do total de entrevistados, $38 \%$ afirmaram ser filiados à AAC (dentre esses, $80 \%$ revelaram avaliar positivamente a atuação desta associação e somente $20 \%$ não acreditam em sua força política). Os $62 \%$ restantes declararam não estar filiados a nenhum sindicato ou associação, por não acreditarem em sua força política, considerando ineficaz a sua atuação, afirmando ainda não ser a mesma capaz de resolver questões importantes concernentes aos artesãos (63\%), e por não conhecer ou saber pouco sobre o papel desempenhado por essa Associação (37\%). Assim, é percebida uma ausência de credibilidade por parte da maioria desses trabalhadores para com a AAC expressando, assim, a intensificação da fragmentação política em um 
contexto de intensificação da precarização das relações de trabalho, conforme mencionado anteriormente.

Dentre os trabalhadores desse referido local, 38,4\% disseram prestar serviços à população (principalmente costuras, em geral); os demais (61,6\%) afirmaram dedicar-se à venda de mercadorias, sendo que os produtos ali comercializados são bastante diversificados (linhas de bordado, artesanatos de madeira, bonecas artesanais, livros, etc.) tanto de fabricação própria (37,5\%), bem como provenientes de outras cidades da região, sobretudo de Maracás e Jequié (62,5\%). Ao que se refere ao mercado de consumo, constatou-se que esse não se restringe apenas a Vitória da Conquista, pois muitos desses produtos são encaminhados para outras cidades da região e até mesmo para outros estados, conforme afirma o Sr. Osvaldo.

Importa ainda mencionar que $\mathrm{ACC}^{3}$ conta atualmente com 65 famílias atuantes e 218 famílias cadastradas tanto de Vitória da Conquista, como também de povoados e demais cidades da região. Entretanto, segundo a Prefeitura Municipal não há no centro comercial principal de Vitória da Conquista, disponibilidade de espaço para o alojamento de todas essas pessoas.

Por parte do Estado a afirmativa é de que não há nas cidades espaços suficientes para o grande número de camelôs, que por sua vez acabam sendo perseguidos por fiscais das prefeituras e policiais, que tem como uma de suas funções fiscalizarem a organização e disposição geográfica dos camelôs no espaço urbano, bem como a procedência dos produtos comercializados. "Se por um lado os fiscais são vistos como carrascos pelos vendedores, por outro lado eles fazem apreensões para assegurar os seus empregos mesmo que isso custe $o$ ganha pão de outros trabalhadores" (SALO, 2008, p. 1). Trata-se da expressão do conflito entre trabalhador personificando o Estado e outro trabalhador personificando o trabalho.

\footnotetext{
${ }^{3}$ Além da AAC, os artesãos de Vitória da Conquista e região podem ainda contar com o apoio do Grupo de Economia Popular (GEP), que foi fundado em 1998, fruto de uma parceria entre a Prefeitura Municipal de Vitória da Conquista (PMVC) e a Universidade Estadual do Sudoeste da Bahia (UESB). Em 2001 o GEP tornou-se uma 'Organização da Sociedade Civil de Interesse Público', pelo Ministério da Justiça, propondo-se a: “oferecer oportunidades para as pessoas que estão fora do mercado de trabalho formal, bem como contribuir para a divulgação e valorização de trabalhos artesanais de produtores locais, em toda região" (OLIVEIRA, 2008, p 11).
} 
Compreende-se que a expansão do comércio informal causa incômodos ao Estado por representar uma perda significativa de tributos (na medida em que esses permanecem nas ruas sem pagamentos de impostos pela circulação de mercadorias, por exemplo) e também ao mercado formal, por representar uma perda de consumidores para este, na medida em que se revela como um concorrente em potencial.

Na Figura 01 pode-se observar a presença de atividades comerciais formais e informais coexistindo no centro comercial conquistense constituindose, assim, em zonas de conflito na luta pelo território.

Figura o1 - Vitória da Conquista/BA: Áreas de comércio informal no centro funcional

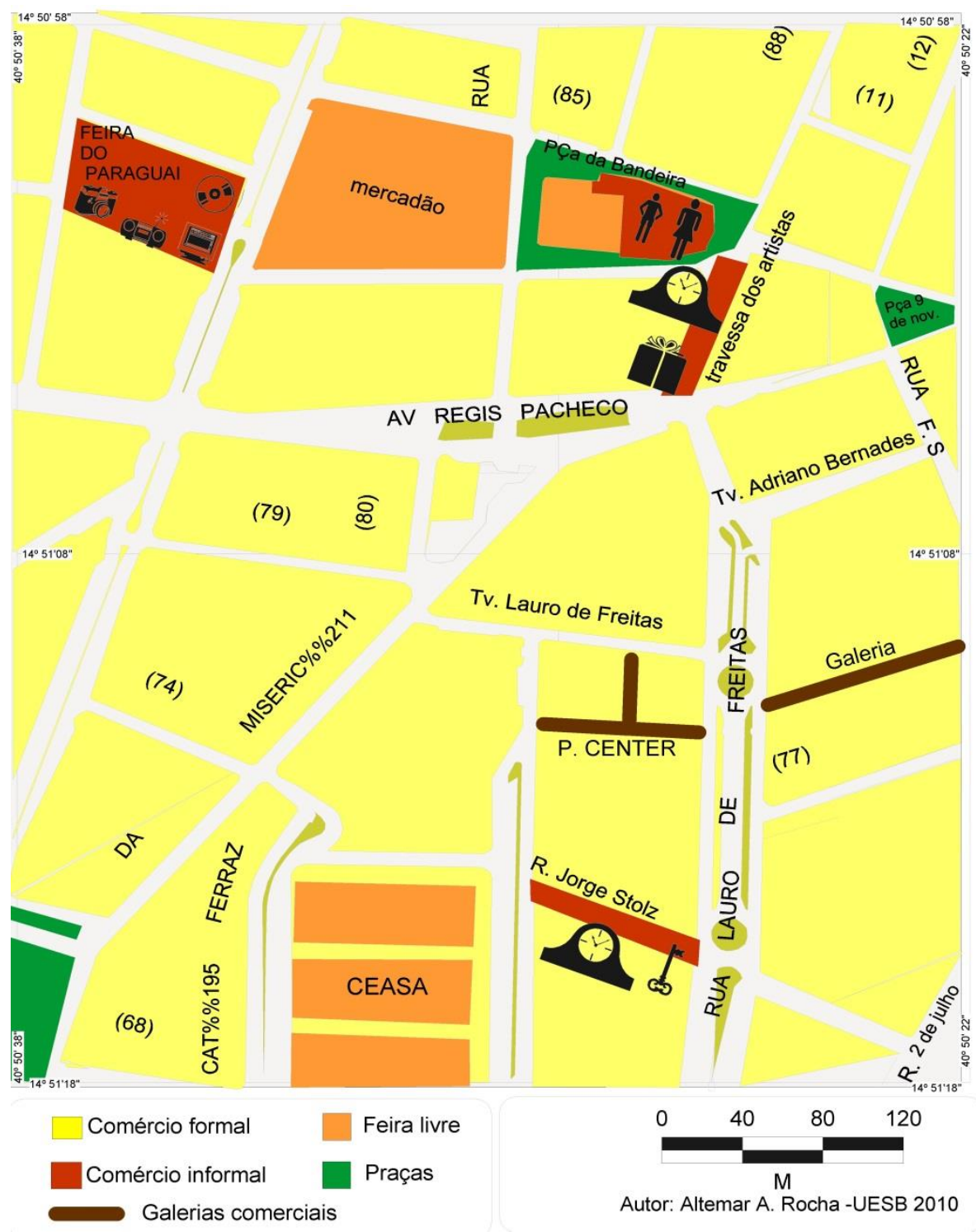

Fonte: Altemar A. Rocha - UESB 
Entende-se ainda que a intensificação da repressão e do controle à "entrada" de novos trabalhadores no comércio ambulante, acaba agravando ainda mais a situação desses que, além de enfrentarem uma grande dificuldade de colocação no mercado de trabalho (pois o mercado encontra-se saturado e é recessivo em força de trabalho), também se deparam com a redução das possibilidades, pelo menos facilmente, de inserção em trabalhos tipicamente desregulamentados, informais de rua (DURÃES, 2007).

O órgão responsável pela administração do Mercado Municipal de Artesanato atualmente é a Secretaria de Serviços Públicos do município (SSP). Seu Osvaldo, porém, não concorda com essa administração, acreditando que a AAC deveria ser mais atuante, segundo ele "deveria receber recursos e poder tomar decisões".

Assim, o que se observa é uma relação de dependência desses trabalhadores à administração do poder público municipal, uma vez que deste procedem os recursos necessários para o funcionamento e manutenção do referido local: serviços relacionados à segurança pública, fiscalização, higienização do local, dentre outros.

\section{CONSIDERAÇÕES FINAIS}

$\mathrm{Na}$ presente pesquisa constatou-se que a abordagem do mundo do trabalho considerando-se a relação intrínseca entre os processos de precarização do trabalho, do desemprego e do fenômeno da informalidade é de fundamental importância, visto que esses se apresentam como reflexo do processo de reestruturação produtiva do capital, que acabou por repercutir em profundas mudanças no mundo do trabalho, na medida em que gera impactos diretos na forma de utilização e exploração intensa dos trabalhadores, conduzindo ainda ao crescimento das taxas de desemprego (em função da expressiva exclusão do trabalho vivo no processo produtivo), bem como a expansão do trabalho informal.

Com relação à ação do Estado sobre o mundo do trabalho, constatou-se a existência de um Estado capitalista moderno que atua enquanto agente regulador, legitimador e ao mesmo tempo limitador do trabalho informal, por meio de seus variados instrumentos de regulação e controle. Assim, verifica-se 
que essa Instituição contribui para com o processo de subordinação e subsunção, inclusive ideológica, do trabalhador à lógica do capitalismo, na medida em que o sujeito (trabalhador ambulante) mesmo ao tornar-se um Microempreendedor Individual, não se isenta da precarização de suas condições de vida e de trabalho.

Foi constatado ainda que, além do Estado, há atuação no espaço urbano capitalista de outros atores sociais (como é o caso dos comerciantes ambulantes, por exemplo) cujas ações e embates refletem interesses e necessidades divergentes entre si na disputa no/pelo território, como pode ser observado no centro comercial principal da cidade de Vitória da Conquista, em qual atividades comerciais formais e informais coexistem.

Esses trabalhadores ambulantes se alojam nas ruas, calçadas, praças públicas, estando sujeitos as mais diversas vicissitudes tais como fiscalização, apreensão de mercadorias, roubos, assaltos, desconforto do local de trabalho, insegurança financeira, discriminação social, intempéries climáticas, dentre outras. Além disso, a maioria deles ainda se veem obrigados a se submeter a longas e intensas jornadas de trabalho, no intuito de atingir uma renda que garanta a sua sobrevivência e de seus familiares.

Assim, compreende-se que o trabalho informal, marcado pela precariedade de suas formas e relações de trabalho, apresenta-se como forma de organização do trabalho desenvolvido pelos sujeitos no intuito de superar as dificuldades de sobrevivência, ao mesmo tempo em que contribuem para a reprodução do capital, consistindo em mão-de-obra abundante e barata, contribuindo para a continuidade do ciclo acumulativo das relações capitalistas e isso em escala cada vez mais ampliada.

\section{REFERÊNCIAS}

ABREU, B. R. de. Um olhar sobre a cidade média de Vitória da Conquista. In: II SIMPÓSIO CIDADES MÉDIAS E PEQUENAS DA BAHIA. Anais... Vitória da Conquista: Universidade Estadual do Sudoeste da Bahia, 2011.

ALVES, A. E. S.; ALMEIDA, J. R. M. de. Trabalho informal em tempos "globalizacionistas". Revista HISTEDBR On-line, Campinas, n. Especial, p.238250, mai. 2009. Disponível em: 
$<$ http://www.histedbr.fe.unicamp.br/revista/edicoes/33e/art15 33esp.pdf >; Acessado em: mai. 2020.

CASTRO, I. E. de. Geografia e Política: Território, escalas de ação e instituições. Rio de Janeiro: Bertrand Brasil, 2005.

CORRÊA, Roberto Lobato. O espaço urbano. São Paulo: Ática, $3^{\circ}$ ed., 1995.

DURÃES, B. J. R. Novas Configurações no Mundo do Trabalho: o que há de novo na informalidade de rua?. Revista Pegada Eletrônica, São Paulo, Vol. 8, n.1, jun. de 2007.

FERRAZ, A. E. de Q. O urbano em construção. Vitória da Conquista/BA: Edições UESB, 2001.

FERRAZ, F. Instituição política. In: Glossário político. 2006. Disponível em: $<$ http://www.politicaparapoliticos.com.br/glossario.php?id_glossario=148>; Acessado em: fev. 2020.

INSTITUTO BRASILEIRO DE GEOGRAFIA E ESTATÍSTICA - IBGE. Brasil em Síntese: Panorama (Vitória da Conquista/BA). 2018. Disponível em: $<$ https://cidades.ibge.gov.br/brasil/ba/vitoria-da-conquista/panorama $>$. Acesso em: mar. 2020.

LIMA, P. V. O centro de Vitória da Conquista/BA e sua centralidade (Projeto de pesquisa). Vitória da Conquista/ BA; DG-UESB, 2008.

MÉSZÁROS, I. Para Além do Capital: Rumo a uma Teoria da Transição. CASTANHEIRA, P. C.; LESSA, S. (Trad.). São Paulo: Boitempo Editorial, $1^{\circ}$ ed., 2002.

OLIVEIRA, E. S. Perfil dos empreendimentos solidários desenvolvidos no Grupo de Economia Popular e Solidária - GEP, na cidade de Vitória da Conquista na Bahia. Revista Estudos do Trabalho, Ano I, nº 2, 2008. Disponível em:

$<$ http://www.estudosdotrabalho.org/PDFs_rret2/Artigo4_2.pdf>; Acessado em: fev. 2020.

PIRES, E. L. S. A recomposição das escalas de governança, Estado e desenvolvimento territorial no Brasil. GeoTextos, Salvador, v.11, n.1, p.113-137, jul. 2015 .

PORTAL DO EMPREENDEDOR. O Microempreendedor Individual MEI. Disponível em: <http://www.portaldoempreendedor.gov.br/duvidasfrequentes $>$; Acessado em: abr. 2020. 
PREFEITURA MUNICIPAL DE VITÓRIA DA CONQUISTA - PMVC. A cidade: Economia. (2015). Disponível em:

<http://www.pmvc.ba.gov.br/economia/>; Acessado em: mar. 2020.

SALO, L. Um breve Histórico do Desemprego. Disponível em: <ttp//www. Lotecultural. com/27/06/20008/sobre-desemprego-e-informalidade-2/>. Acessado em: set. 2008.

SERVIÇO BRASILEIRO DE APOIO ÀS MICRO E PEQUENAS EMPRESAS SEBRAE. Tudo o que você precisa saber sobre o MEI.

Disponível em: <https://m.sebrae.com.br/sites/PortalSebrae/sebraeaz/o-quee-ser-mei,eoba13074c0a3410VgnVCM1000003b74010aRCRD>. Acessado em: abr. 2020.

SOARES, M. A. T. Trabalho informal: da funcionalidade à subsunção ao capital. Vitória da Conquista, BA: Edições UESB, 2008. 152 p.

SOUZA, M. L. de. Mudar a cidade: uma introdução crítica ao planejamento sobre a gestão urbana. Rio de Janeiro: Bertrand Brasil, 2006.

TAVARES, D. Lideranças comemoram abertura do Empreendedor Individual para todo o País. In: PORTAL ADMINISTRADORES. Disponível em: <http://www.crcsc.org.br/comunicacao/noticias_ler.php? idnoticia=594>; Acessado em: jan. 2020.

VIANA, M. A. C. Mecanismos de participação e fiscalização do orçamento público: a experiência do orçamento participativo de Vitória da Conquista. 2009. 90 f. Dissertação (Mestrado em Ciências sociais) - Pontifica Universidade Católica de São Paulo - PUC, São Paulo, 2009.

VITÓRIA DA CONQUISTA (Município). Lei $\mathbf{n}^{\circ} 695$ de o2 de fevereiro de 1993. Dispõe sobre o Código de Polícia Administrativa (Código de Posturas), do município de Vitória da Conquista/BA. Disponível em:

$<$ https://www.pmvc.ba.gov.br/wp-content/uploads/Lei-695-1993-

Codigo Policia Administrativa-codigo-de-posturas.pdf $>$; Acessado em: abr. 2020.

VITÓRIA DA CONQUISTA (Município). Lei no 1.259 de 22 de dezembro de 2004. Dispõe sobre o Código Tributário do município de Vitória da Conquista/BA. Disponível em:

<https://sogi8.sogi.com.br/Arquivo/Modulo113.MRID109/Registro18336/lei\% 20n\%C2\%BA\%201.259,\%20de\%2022-12-2004.pdf>; Acessado em: abr. 2020.

VITÓRIA DA CONQUISTA (Município). Lei no 1.385 de 26 de dezembro de 2006. Dispõe sobre o Plano Diretor do Município de Vitória da 
Conquista/BA. Disponível em: <http://www.pmvc.ba.gov.br/wpcontent/uploads/Lei 1385 o6 Plano-Diretor-Urbano1.pdf >; Acessado em: abr. 2020. 